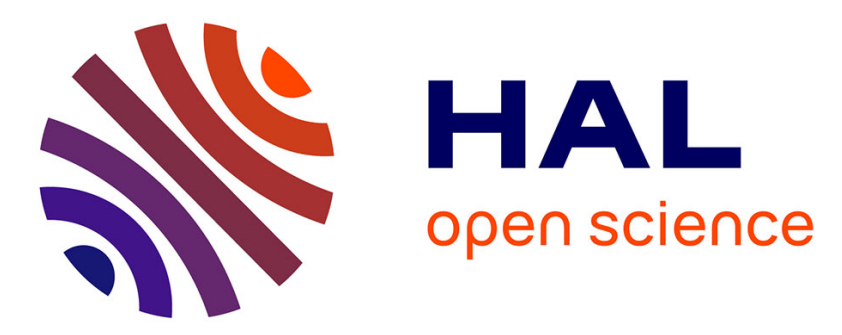

\title{
New millimeter wave generation scheme for MIMO-OFDM based Radio-over-Fiber system
}

M. El Yahyaoui, A. El Moussati, Ghaïs El Zein, Kamel Haddadi

\section{To cite this version:}

M. El Yahyaoui, A. El Moussati, Ghaïs El Zein, Kamel Haddadi. New millimeter wave generation scheme for MIMO-OFDM based Radio-over-Fiber system. Optics Communications, 2019, 442, pp.101105. 10.1016/j.optcom.2019.03.017 . hal-02089125

\section{HAL Id: hal-02089125 \\ https://hal-univ-rennes1.archives-ouvertes.fr/hal-02089125}

Submitted on 11 Apr 2019

HAL is a multi-disciplinary open access archive for the deposit and dissemination of scientific research documents, whether they are published or not. The documents may come from teaching and research institutions in France or abroad, or from public or private research centers.
L'archive ouverte pluridisciplinaire HAL, est destinée au dépôt et à la diffusion de documents scientifiques de niveau recherche, publiés ou non, émanant des établissements d'enseignement et de recherche français ou étrangers, des laboratoires publics ou privés. 


\title{
New millimeter wave generation schem $f_{r}$ MIMO-OFDM based Radio-over-Fiber sy ${ }^{+}$en
}

\author{
Moussa El Yahyaoui ${ }^{\mathrm{a}}$, Ali El Moussati ${ }^{\mathrm{a}}$, Ghaïs El Zein ${ }^{\mathrm{b}}$, '’amel Haddadic \\ ${ }^{a}$ Department of Electronics, Informatics and Telecommunica ions, E. 'SAO, University \\ Mohammed Premier, Oujda, Morocc \\ ${ }^{b}$ Institute of Electronics and Telecommunicatior, of Renines, France. \\ ${ }^{c}$ University Lille, CNRS, UMR 8520 - IEMN, '-50 JU 'ille, France.
}

\begin{abstract}
This paper proposes a new scheme for the reneration and transmission of a MIMO-OFDM signal over optical fib ${ }^{n}$ using a single local oscillator (LO) at $15 \mathrm{GHz}$. This technique is based o. abcarrier multiplexing and Optical Carrier Suppression (OCS) mo ' 'atic ' using both Dual-Parallel MachZehnder Modulator (DP-MZM) and Dusl-Drive Mach-Zehnder Modulator (DD-MZM). DP-MZM is used to nuivi, lex the MIMO-OFDM signals while DD-MZM is used to generate the $9 \mathrm{c}^{\mathrm{CHz}} \mathrm{Hz}$ signal by quadrupling. The realistic and global simulation 1 i. complete system is performed to predict the behavior of a Radio c rer Fib or (RoF) system prior to its realization. The optical and wireless chan.. 's' are based on Single Mode Fiber (SMF) and Triple-S-and-Valen uel. (TSV) models, respectively. We have exploited the allocated $7 \mathrm{GHz}$ ir the $90 \mathrm{r}, \mathrm{Hz}$ band for unlicensed use and we have successfully achieved 5 , $m$ SMF followed by $3 \mathrm{~m}$ wireless link at $70 \mathrm{~Gb} / \mathrm{s}$. In comparison with tradition 1 methods, the technique proposed combines better performance $t \mathrm{r} r$ latively low-cost.
\end{abstract}

Keywords: 6r GHz, MIMO, OFDM, Radio over Fiber, MMW generation.

\section{Intror'uction}

Over $\mathrm{t} \cdot \mathrm{l}$ las ${ }^{\dagger}$ decade, there has been a lot of interest to achieve the highest data sroughput. In this context, Multiple-Input Multiple-Output (MIMO) techr logy $\mathrm{l}$ as proven its ability to improve data rate. However, the implementatı... of MIMO technology has been usually restricted to the microwave raı xe $<\delta G H z)$ resulting in limited data rate below few Gb/s. Therefore, 
the transition to higher frequency range, specifically the $60 \mathrm{GF}_{\mathbf{L}_{2}}$ hs $\mathrm{hd}$, is considered by standardization organizations as a viable alterna 've tu respond to the need of high data rate. In particular, new standar is fores $2 n$ in this frequency range are capable of delivering data rate up t) $7 \mathrm{C} . \mathrm{D} / \mathrm{w}(802.11$.ad and 802.15.3c) [1]. However, the signals transmitted in this and suffer from a strong attenuation related to free-space propagatior losse and multiple reflections due to the possible presence of obstacles. $T_{\perp} 1 \mathrm{~s}$, th : radio coverage is generally limited to a few meters in the indoo environment. To extend this coverage to an entire building or a large art ^. technology is considered.

Radio over Fiber has been widely described in $\mathrm{i}$ e literature as a viable solution for transporting MIMO signals. Inde d $\mathrm{P} J \mathrm{~F}$ allows the transport of multiple RF signals over single optical fibe from central office to base station. Various techniques have been de "ribed to transport MIMO signals over fiber [2-7]. Among them, we find the pow rization-division-multiplexing (PDM) [2, 3], optical subcarriers mus 'ol' xı!g [4-6], or PDM with optical heterodyne up-converter at base st tion 7]. However, these techniques use more than one high-frequency local 1 s $\mathrm{c}_{1}{ }^{2} \mathrm{t}$ tor (up to $40 \mathrm{GHz}$ ). In this work, we introduce a new technique the $h_{1}-l_{r}$; use of only one oscillator operating at $15 \mathrm{GHz}$. In addition, this techniqu offers better performances compared to those used in [5] and [6].

The MIMO channel me tel use ! in this work is based on TSV model [8]. This model was proposed by $\mathrm{L}$, $\mathrm{S}$ ational Institute of Information and Communication Technology NIr , T) - Japan to the 802.15.3c Channel model subgroup. TSV is a statistic me del whose basic assumption is that multipath components arrive ir clusters in both the temporal and spatial domains [9]. This model incorporates ' me of the antenna parameters within the channel accounting for th $\mathrm{er}$ effects. We have used the model of Desktop environment which is a cal office desktop and computer cluster [10]. Compared to previous $\mathrm{w}$ rks $[5,5]$ and considering in this paper a more precise channel model, $\mathrm{v}>\mathrm{p}$ opc e in this work a global architecture including a hybrid system in the ${\mathrm{O}_{1}}^{+i}$ al and wireless regimes for communications around 60 $\mathrm{GHz}$. Th : beha ior prediction of such system is carried out by a global simulation us ng th : real characteristics of the functions: baseband, optical/RF and $\mathrm{t}$ ansmission environment. To validate our approach, we have evaluated and ( ompar d our technique that uses one LO with the method based on two LUs, in function of bit error rate (BER) performance and optical power $\operatorname{spe}^{2} \operatorname{tr}$ ill. 
The rest of this paper is organized as follows: Section 2 pre $n^{\prime} \uparrow$, the $2 \times 2$ MIMO-RoF proposed system. Section 3 describes its theo +icas nalysis. Next, Section 4 presents the results obtained by simulati. F. Fin illy, some concluding remarks are given in Section 5 .

\section{Principle of the proposed system}

The proposed $2 \times 2$ MIMO-RoF architectur, is prcoented in Fig. 1 . The OFDM complex baseband signals, $I_{j}-O F L M$.nd $Q_{j}-O F D M$ (with $\mathrm{j}=1,2$ ), were generated using Matlab/Simulink and thor sampled at $10 \mathrm{GS} / \mathrm{s}$. These signals are obtained by mapping binary da. a into QPSK, 16QAM, or 64QAM.The mapped data is coded using V V itical-Bell Laboratories Layered Space-Time (V-BLAST) coder, whl' corresponds to spatial multiplexing technique, to form two OFDI syilas. Two training sequences are inserted before the Inverse Fast Fourier 1 ansform (IFFT) operation for channel estimation at receiver. The O, UN . wnal is obtained by using FFT of 512 points with a cyclic prefix ( $\mathrm{CP})$ o. 1/8 symbol time, and 355 subcarriers which corresponds to $6.93 \mathrm{GHz}$ ba dwidth. The principle of the used RoF downlink, with an optical c $\therefore$. 1.") transmitting two RF OFDM $\left(R F_{1}\right.$ and $R F_{2}$ ) signals, is based on dual $\mu$ rallel MZM (DP-MZM) and dual drive MZM (DD-MZM). The OFDм baseband signals are up-converted electrically to $f_{L O}=15 \mathrm{GHz}$ usins $\mathrm{I} / \mathrm{Q} \mathrm{L}$ ixers. The converted signals are coupled through a $90^{\circ}$ hybrid corple $T^{\prime}$ e DP-MZM is polarized to its minimum transmission bias point io ' talize optical carrier suppression (OCS) modulation and the used par ${ }^{2}$ eter, are shown in Table 1. This MZM is driven by the combined sigr tls to mıdulate the optical carrier and to multiplex the subcarriers as depic ced 1 . inset $(b)[6,11]$.

In order to ge te te $60 \mathrm{GHz}\left(4 \times f_{L O}\right)$ from optical heterodyne in photodetector, a DD- IZ! 1 is used to generate two subcarriers, spaced by $90 \mathrm{GHz}$ (inset d'), to $\mathrm{r}$ \& comı ' ned with the multiplexed RF-OFDM subcarriers (inset c) [12]. The mu'ipl xed subcarriers, depicted in inset (e), are transported from central sta: ${ }^{\prime} r$ to base station through a single mode optical fiber. The received ' ptica' signal at base station is interleaved to separate the two RFOFDM c npon nts of $2 \times 2$ MIMO signal. Finally, the interleaved signals are cc . verted in the electrical domain using two photodiodes. An interleaver is use $\mathrm{t}$ after DD-MZM to delete the unused subcarriers of frequency $f_{c}+f_{L O}$ and $f_{c} \quad f_{\nu} O$ (an optical filter can be used). 


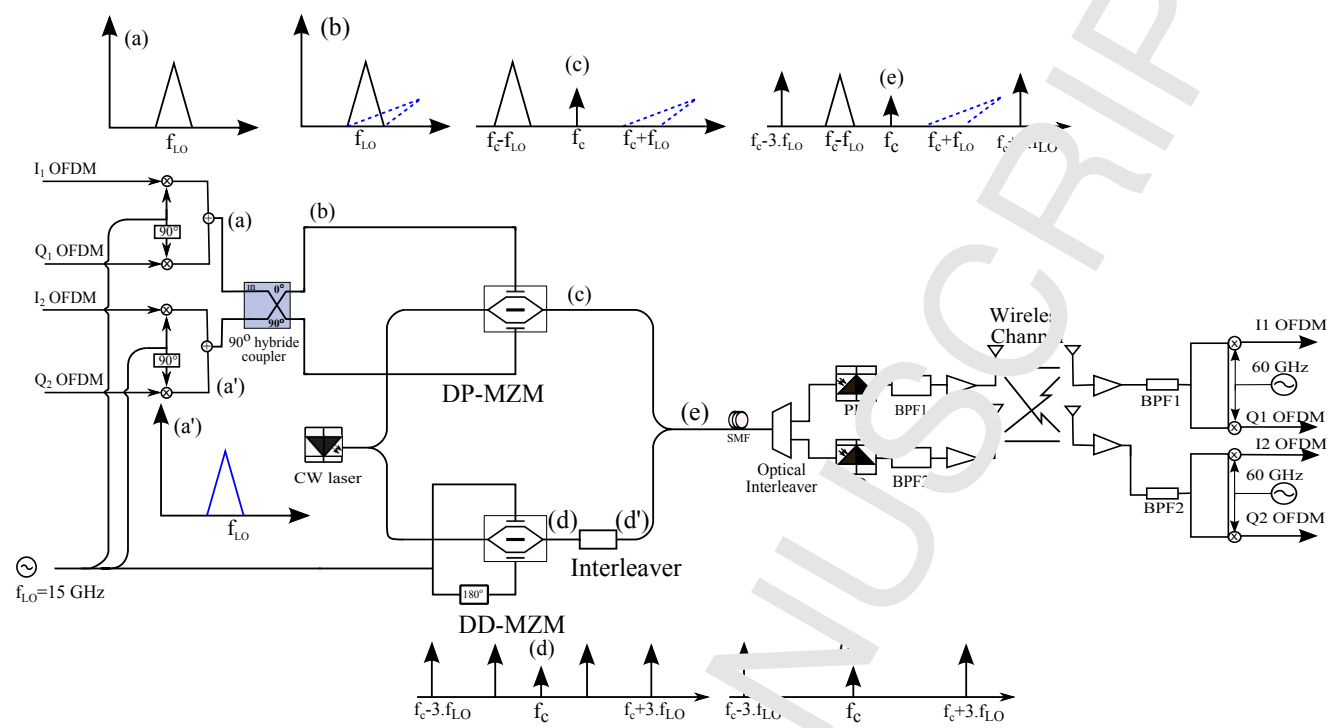

Figure 1: Schematic princip a the proposed system

\begin{tabular}{|c|c|}
\hline Parameter & Value \\
\hline Extinctio: $\ldots+{ }^{+ \text {in }}$ & $30 \mathrm{~dB}$ \\
\hline Switching bian voltage & $4 \mathrm{~V}$ \\
\hline Switchin $r$ RF voltage & $4 \mathrm{~V}$ \\
\hline Bias voltag, 1 & $0 \mathrm{~V}$ \\
\hline Birs vu' $\neg g ; 2$ & $4 \mathrm{~V}$ \\
\hline
\end{tabular}

Tabl 1: ara teters of DP-MZM modulator

\section{Theoretical aisalys.}

The signal g ner ated from the DD-MZM, inset (d) of Fig. 1, has the optical field $E_{u t}(t$, tefined as

$$
E_{\text {out }}\left(\iota,-E_{i},(t) \exp \left[j \beta \cos \left(\omega_{m} t+\varphi\right)\right]+\exp \left[j \beta \cos \omega_{m} t+j \phi_{0}\right]\right.
$$

where $E_{l}(t)=\Psi_{c} \exp \left(j \omega_{c} t\right)$ is the optical carrier, $j^{2}=-1, E_{c}$ represents the amplit. $\lambda_{\rho} J_{c}$ is the angular frequency of the optical carrier $\left(\omega_{c}=2 \pi f_{c}\right)$, $\beta$ is ne me dulation index of the DD-MZM, $\Delta \varphi$ is the phase difference of RF $s$ rnal a splied to two arms of DD-MZM, $\phi_{0}$ is the phase obtained by adinating the DC bias of DD-MZM, $\omega_{m}$ is the angular frequency for the RF 
signal. From Jacobi-Anger expansion [12], Eq. (1) has the foi. , c

$$
E_{\text {out }}(t)=E_{c} \sum_{n=-\infty}^{+\infty} j^{n} J_{n}(\beta) \exp \left[j\left(\omega_{c}+n \omega_{m}\right) t\right] \exp (j n \Delta)+\cdots n\left(j \phi_{0}\right)
$$

where $J_{n}(\beta)$ is the nth Bessel function of the first ki d.

Since the sidebands of order $3^{r d}, 2^{\text {nd }}, 1^{\text {st }}, 0^{\text {th }},+1^{t}+2^{r l}$, and $+3^{r d}$ are of the most importance for our modulation, we lis - the aptical fields of these sidebands as follows:

$$
\begin{aligned}
& E_{-3}=E_{c} \exp \left(j \frac{3 \pi}{2}\right)\left[J_{3}\left(\beta_{1}\right) \exp (-j 3 \varphi)+J_{3}\left(\beta_{2}\right) \exp \left(; \phi_{0}\right)\right] \exp \left[j\left(\omega_{c} t-3 \omega_{e} t\right)\right] \\
& E_{-2}=E_{c} \exp (j \pi)\left[J_{2}\left(\beta_{1}\right) \exp (-j 2 \varphi)+J_{2}\left(\beta_{2}, \operatorname{xpp}\left(j \phi_{0}\right)\right] \exp \left[j\left(\omega_{c} t-2 \omega_{e} t\right)\right]\right. \\
& \left.E_{-1}=E_{c} \exp \left(j \frac{\pi}{2}\right)\left[J_{1}\left(\beta_{1}\right) \exp (-j \varphi)+J_{1}{ }^{\prime}{ }^{\prime}\right) \exp \left(j \phi_{0}\right)\right] \exp \left[j\left(\omega_{c} t-\omega_{e} t\right)\right] \\
& E_{0}=E_{c}\left[J_{0}\left(\beta_{1}\right)+J_{0}\left(\beta_{2}\right) \exp \left(j \phi_{0}\right)\right] \exp _{\Upsilon^{\top}{ }^{\top} \omega_{c^{\prime}} \text {; }} \\
& E_{+1}=E_{c} \exp \left(j \frac{\pi}{2}\right)\left[J_{1}\left(\beta_{1}\right) \exp (j \varphi) \quad I_{1}\left(\beta_{c^{\prime}}\right) \exp \left(j \phi_{0}\right)\right] \exp \left[j\left(\omega_{c} t-\omega_{e} t\right)\right] \\
& E_{+2}=E_{c} \exp (j \pi)\left[J_{2}\left(\beta_{1}\right) \exp \left(j 2 \div \perp \ldots\left(\beta_{2}\right) \exp \left(j \phi_{0}\right)\right] \exp \left[j\left(\omega_{c} t-2 \omega_{e} t\right)\right]\right. \\
& E_{+3}=E_{c} \exp \left(j \frac{\pi}{2}\right)\left[J_{3}\left(\beta_{1}\right) \exp (j 3 \varphi)+J_{3}\left(\beta_{2}\right) \exp \left(j \phi_{0}\right)\right] \exp \left[j\left(\omega_{c} t-3 \omega_{e} t\right)\right]
\end{aligned}
$$

The corresponding optic $₫$ powe, are:

$$
\begin{aligned}
& P_{-3}=E_{c}^{2}\left[J^{2}\left(\beta_{1},+{ }_{3}^{2}\left(\beta_{2}\right)+2 J_{3}\left(\beta_{1}\right) J_{3}\left(\beta_{2}\right) \cos \left(3 \varphi+\phi_{0}\right)\right]\right. \\
& \left.\left.P_{-2}=E_{c}^{2 \Gamma} J_{2}^{2}, \beta_{1}\right)+J_{2}^{2}\left(\beta_{2}\right)+2 J_{2}\left(\beta_{1}\right) J_{2}\left(\beta_{2}\right) \cos \left(2 \varphi+\phi_{0}\right)\right] \\
& \left.P_{-1}=F_{c}^{2\ulcorner} J_{1}^{2}\left(\beta_{1}\right)+J_{1}^{2}\left(\beta_{2}\right)+2 J_{1}\left(\beta_{1}\right) J_{1}\left(\beta_{2}\right) \cos \left(\varphi+\phi_{0}\right)\right] \\
& P_{0}={ }^{2}\left[J^{\prime}\left(\beta_{1}\right)+J_{0}^{2}\left(\beta_{2}\right)+2 J_{0}\left(\beta_{1}\right) J_{0}\left(\beta_{2}\right) \cos \left(\phi_{0}\right)\right] \\
& P_{+1}=E_{c}^{\dot{\alpha}}\left[\nu_{1}^{-2}\left(\beta_{1}\right)+J_{1}^{2}\left(\beta_{2}\right)+2 J_{1}\left(\beta_{1}\right) J_{1}\left(\beta_{2}\right) \cos \left(\varphi-\phi_{0}\right)\right]
\end{aligned}
$$

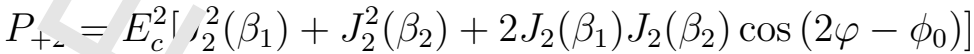

$$
\begin{aligned}
& { }^{-}+3=L_{c}\left[J_{3}^{2}\left(\beta_{1}\right)+J_{3}^{2}\left(\beta_{2}\right)+2 J_{3}\left(\beta_{1}\right) J_{3}\left(\beta_{2}\right) \cos \left(3 \varphi-\phi_{0}\right)\right]
\end{aligned}
$$

In ordt to $r$ stain an OCS modulation with the even sidebands order suppress $^{\prime} \mathrm{d}$ (in ur case $2^{\text {nd }}, 0^{\text {th }},+2^{\text {nd }}$ order sidebands), the following conditions shoul' 'be vf ified 


$$
\begin{aligned}
& \cos \left(\phi_{0}\right)=-1 \\
& \cos \left(2 \varphi-\phi_{0}\right)=-1 \\
& \cos \left(2 \varphi+\phi_{0}\right)=-1 \\
& \beta_{1}=\beta_{2}
\end{aligned}
$$

From $(5)$, we have $\beta_{1}=\beta_{2}, \varphi=\pi(\bmod 2 \pi)$, and $0=\pi(\bmod 2 \pi)$. Thus, the OCS modulation can be realized by means of a $18^{r}, \mathrm{~h}$ brid coupler and a dual-drive MZM by a proper DC bias, which inı 'ndu, an additional phase difference of $\pi$ between the two arms of the dual-drı re MZM.

\section{Simulation results and discussion}

The simulation of the proposed system is , erformed with a cosimulation technique using MATLAB/Simulink a $d \nu^{\prime}$ uiSystem. The simulations results are depicted in this section. We $\perp$ ave started by fixing the optimal optical power injected in the optica. nulators to avoid operation in the nonlinearity regime of optical c ${u_{\Gamma}}_{n} n_{t}$ nts. Indeed, we have calculated the EVM performance at the receiver $\left(\mathrm{h}^{-}{ }^{-}\right)$for each value of optical power at the transmitter (Tx), as shown in Fig. 2. We have obtained 10dBm as optimal

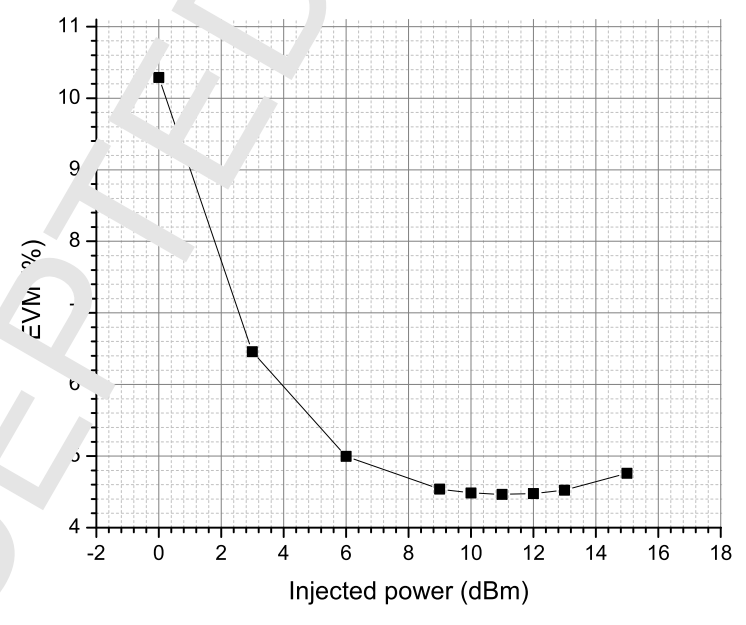

, igure 2: EVM variation in function of injected optical power

Vi uu, hich corresponds to the minimum of EVM and optical power. The 

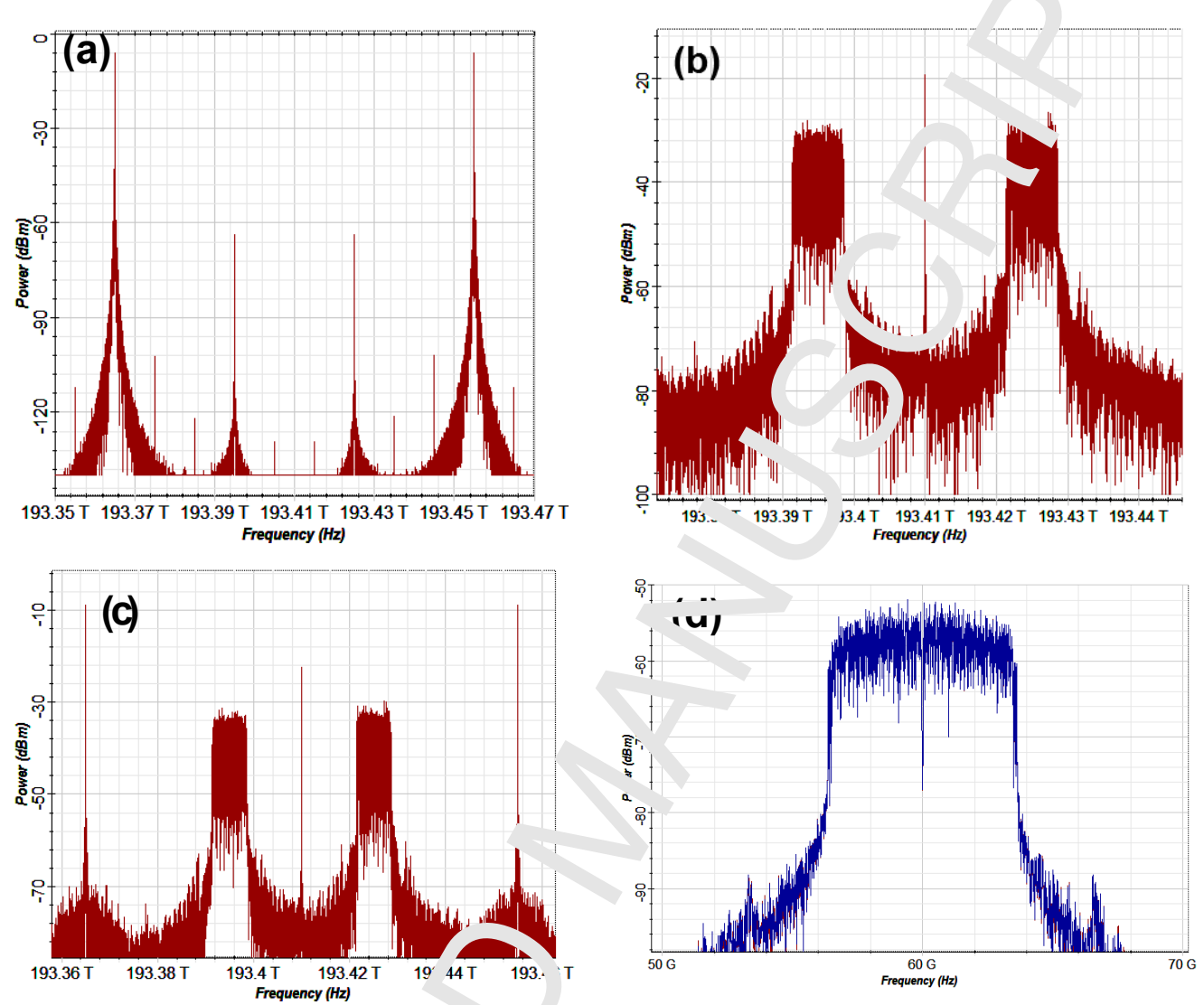

Figure 3: a) Generated subc rrie s witı 90GHz separation, b) Multiplexed subcarriers, c) Combined optical signal, d, $\mathrm{Sp}^{\prime} \mathrm{ctru}+\mathrm{at}$ reception $(25 \mathrm{~km})$

EVM is calculated or bu'-m SMF with, high efficiency, 64QAM modulation scheme. Fig. 3 , no is the optical spectrum of generated subcarriers with $90 \mathrm{GHz}$ separati ( ), the multiplexed subcarriers of OFDM-MIMO signals (b), the comb; led op : cal signal (c) to be transported throught optical fiber, and the frec 'en' $y \mathrm{~s}^{r}$ ectrum of millimeter wave at reception after photodetector.

For o' $\mathrm{r}$ simu'ations, the $2 \times 2 \mathrm{MIMO}$ channel is developed in our previous research $\left[{ }^{\circ}\right] \mathrm{wh}^{\circ} \mathrm{h}$ is based on TSV model [10]. To create sufficient antenna decor elation, the transmitting and receiving antennas were separated by 9 $\mathrm{cm}$ a. d $5 \mathrm{cn}$, respectively [6]. The considered radio link has $3 \mathrm{~m}$ of distance between $-\Lambda$ and Rx. In Fig. 4, we show the variation of BER in function of 'Dt' $\mathrm{ca}$ fiber length at fixed signal-to-noise ratio Eb/No of $7 \mathrm{~dB}$. From this 
value, performance of $70 \mathrm{~Gb} / \mathrm{s}$ using a 64QAM modulation scht. ne s achieved over, up to, $42 \mathrm{~km}$ of SMF length with a BER of $10^{-3}$.

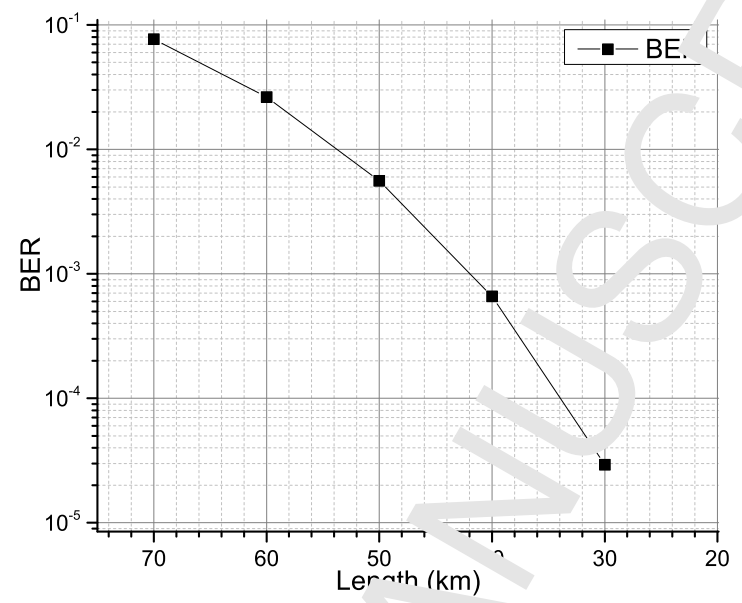

Figure 4: BER in function of $\mathrm{SN}^{\top}{ }^{\top}$ length for $\mathrm{Eb} / \mathrm{No}=7 \mathrm{~dB}$

Then, we have calculated the nerfo mance of the system for $50 \mathrm{~km}$ SMF, using different modulation schemes. The modulations used are QPSK, 16QAM, and 64QAM, which correspond to bit rates of $23.32 \mathrm{~Gb} / \mathrm{s}, 46.66 \mathrm{~Gb} / \mathrm{s}$, and $70 \mathrm{~Gb} / \mathrm{s}$, respectively. Thesf resuı, , are obtained without using channel coding. Fig. 5 shows the pertu nanc: of $2 \times 2$ MIMO-RoF for different modulations. These results : ie rbtaııed for $50 \mathrm{~km}$ SMF followed by $3 \mathrm{~m}$ wireless

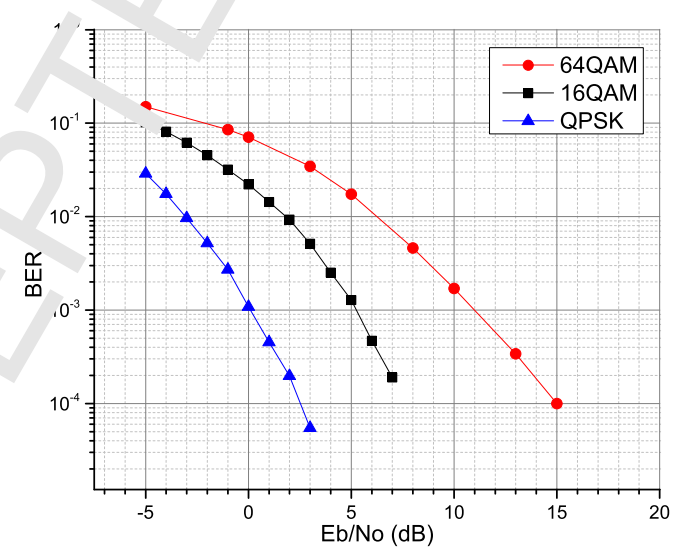

. gure 5: Variation of BER in function of modulation and $\mathrm{Eb} / \mathrm{No}$ 
channel.

For comparison purpose, we have also simulated a syste.. base ${ }^{1}$ on two LO $(25 \mathrm{GHz}$ and $35 \mathrm{GHz})$ as in [5]. This comparison is . te th the same conditions and with the same parameters in terms of me tuls uloı, data rate, and optical power. As we can see in Fig. 6, the optical sp trum obtained with the proposed system, using a single LO (15GH ^) (in 'lue), shows low attenuation of the optical power. Indeed, a differenc of $10 \mathrm{~dB}$ between the generated spectra is noticed.

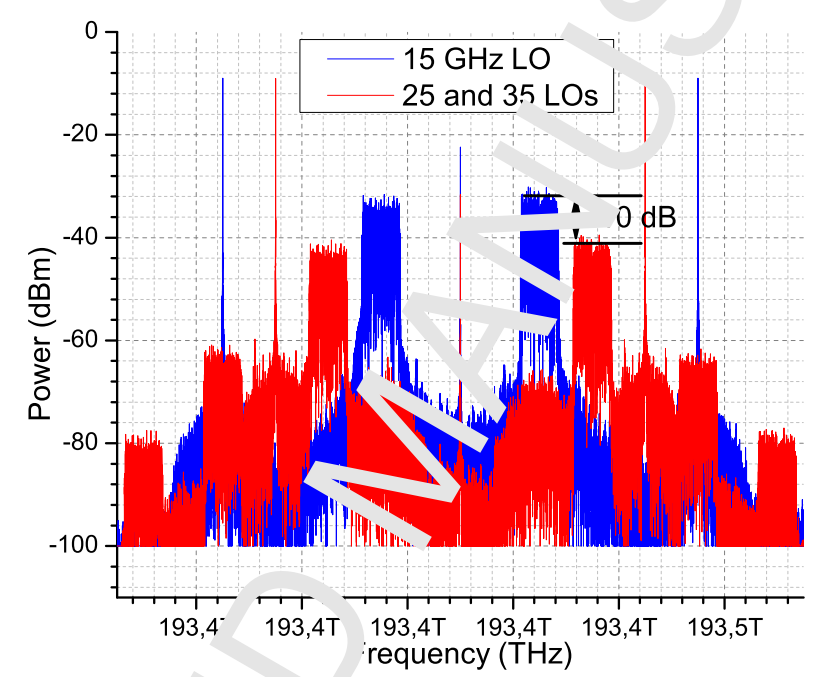

Figure 6: Optical spectra of he 'ultiplexed subcarriers in both cases: with one LO (blue) and with two LOs (red)

We have also ccmpan the transmission performance of a $2 \times 2$ MIMO system at $70 \mathrm{~Gb} / \mathrm{s}$ w. h SMF fiber of $25 \mathrm{~km}$, as shown in Fig. 7. This comparison is performec hy sing 64QAM, 16QAM, and QPSK modulation schemes, which allows $v$, to st, aasily the difference between the performances of studied systems. As ve ran see, our system offers better BER performance. Indeed, consider $\iota_{\iota_{c}}$ P $\mathrm{P} \mathrm{ER}=10^{-3}$, a gain of $10 \mathrm{~dB}$ in term of $\mathrm{Eb} /$ No is noticed. Moreover by ce mparing these results with those obtained experimentally in [5], where they ave used two LOs, we concluded that our system has better pe surmance. Indeed, the authors in [5] have transmitted $61.5 \mathrm{~Gb} / \mathrm{s}$ data rate ignal $v$ ith BER of $10^{-3}$ over $25 \mathrm{~km}$ SMF transmission followed by $3 \mathrm{~m}$ wireles ${ }^{+}$.nsmission, while we have transmitted $70 \mathrm{~Gb} / \mathrm{s}$ over $50 \mathrm{~km}$ SMF for 'owe i'y a $3 \mathrm{~m}$ wireless transmission. 


\section{Conclusion}

This paper presents the design and simulation of a now 4 - 2 MIMO OFDM-RoF system architecture based on a single oscil' ${ }^{\prime}$ tor ${ }^{2}{ }^{\prime} 15 \mathrm{GHz}$. In addition to the simplicity and relatively low-cost of the pr. $\mathrm{pr}_{\mathbf{r}}$ - sed solution, the results obtained demonstrate better performance comr aled to inose obtained using an architecture based on two oscillators. In, articu tr, the solution proposed can achieve data rate of $70 \mathrm{~Gb} / \mathrm{s}$ over $5 \mathrm{nk}_{\mathrm{kn}}{ }^{\mathrm{Cr}}{ }_{1} \mathrm{~F}$ followed by a $3 \mathrm{~m}$ wireless transmission. This performance imp ove $\mathrm{te} t$ is due to the gain provided in terms of optical power generated.

\section{References}

[1] R. Bhusal, S. Moh, Qualitative and Cusnt, itive Comparison of IEEE 802.15.3c and IEEE 802.11ad for Mu '-Gbps Local Communications, Wireless Pers Commun, 75 (2014) 1.

[2] M.A. Elmagzoub, A. Bakar Mo' nma t, R.Q. Shaddad, S.A. Al-Gailani, Polarization multiplexing of two $(1 \ldots$ ro RoF signals and one baseband signal over a single waveleng $\eta^{n}, \hat{\beth}_{\mathbf{r}}$ ics \& Laser Technology, 76 (2016) 70-78.

[3] H. Huang, C. Sun, C. Lin, ( Wei, W. Zeng, H. Chang, B. Shih, A. Ng'oma, Direct-Detertioı. PГ M-OFDM RoF System for 60-GHz $2 \times$ MIMO Wireless Tr nsr ission Without Polarization Tracking, Journal of Lightwave Technu: y, ? J (2018) 3739-3745.

[4] C. Ho, W. Jiar s, ? Sambaraju, W. Lee, T. Lu, C. Wang, H. Yang, C. Lin, C. Wei , C. Chi, A. Ngoma, Performance Evaluation of a $60 \mathrm{GHz}$ Radio-over-F، ber System Employing MIMO and OFDM Modulation, Ieee J Sel Area Conı. ^. 31 (2013) 780-787.

[5] C.-H. Li., ,.-T Lin, H.-T. Huang, W.-S. Zeng, S.-C. Chiang, H.-Y. Chang $20-G_{1}$, optical/wireless MIMO system integrated with optical subce rier $\mathrm{m}$ ltiplexing and $2 \times 2$ wireless communication, Opt Express, $23(20+)^{\sim} 111-12116$.

[6] N. El Yc ayaoui, A. El Moussati, G. El Zein, On the capacity of MIMOOFL... Dased diversity and spatial multiplexing in Radio-over-Fiber syster „, Jpt Commun, 402 (2017) 252-259. 
[7] J. Yu, X. Li, N. Chi, Faster than fiber: over 100-Gb/s sig, ^l telivery in fiber wireless integration system, Opt Express, 21 (2013) ?7,88 22904.

[8] Y. Shoji, H. Sawada, C.S. Choi, H. Ogawa, A Modif ed ‘ Model Suitable for Line-of-Sight Desktop Usage of Millimeter-Wav NPAN Systems, IEEE Transactions on Antennas and Propagation or (?0uY) 2940-2948.

[9] S. Hirokazu, S. Yozo, C. Chang-Soon, Proposal of , nel statistic channel model for millimeter wave WPAN, 2006 Asia Pac: Microwave Conference2006, pp. 1855-1858.

[10] SK. Yong, et al., TG3c Channel Modeling Sub-c mmittee Final Report, IEEE802.15-07-0584-01-003c Mars 2017 2uc

[11] Z. Zheng, M. Peng, H. Zhou, M. Cl .., L. viang, L. Tan, X. Dai, Y. Xiang, Optical single sideband millimeter-w ve signal generation and trans-

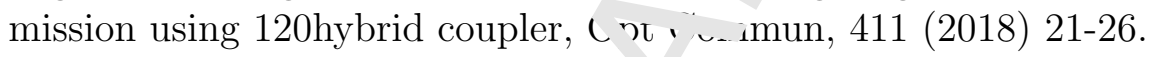

[12] M. Xue, S. Pan, Y. Zhao, Op 'c 1 S. gle-Sideband Modulation Based on a Dual-Drive MZM and a $120^{\circ}$; ' Hyorid Coupler, Journal of Lightwave Technology, 32 (2014) 3317-30²? 


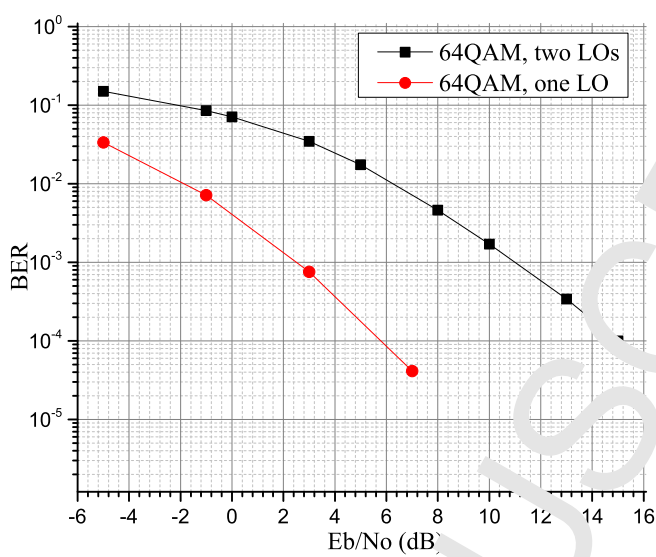

(a) BER comparison for $u$ '?A $v_{\Perp}$ modulation

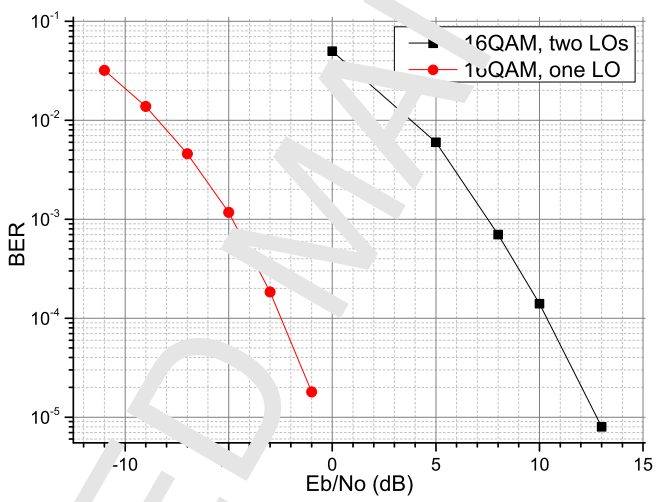

(b) $\mathrm{b}_{\perp}^{\top}$ co aparison for 16QAM modula ion

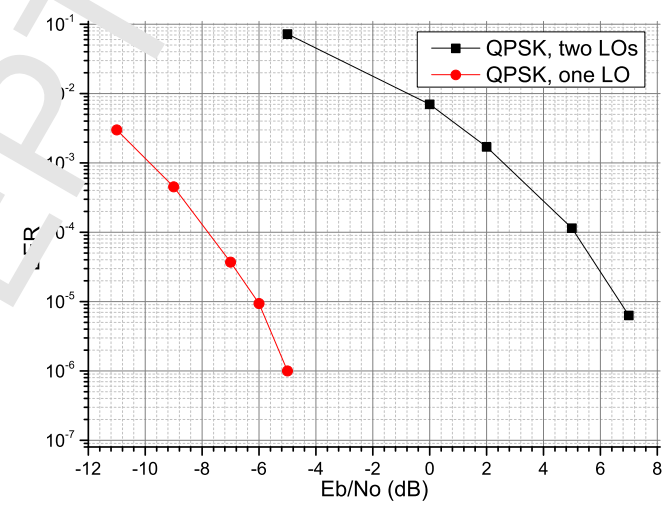

(c) BER comparison for QPSK modulation

Figure 7: BER comparison betw2en using one LO and two LOs 
- New scheme for 2x2 MIMO-OFDM RoF using a single local oscillator

- A realistic and global simulation of 2x2 MIMO-OFDM RoF system is proposed.

- Low-cost technique for Radio over Fiber system 